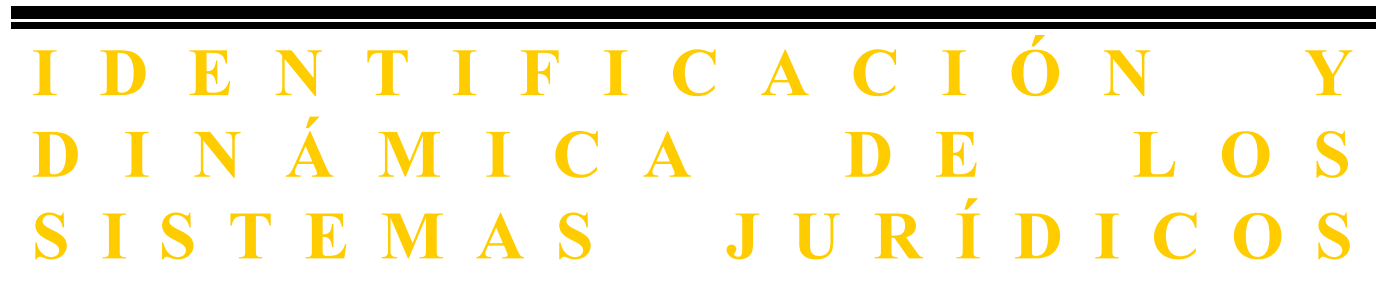




\section{SOBRE OBSERVADORES Y PARTICIPANTES}

. En un brillante artículo Juan Carlos Bayón ${ }^{1}$ defiende la tesis, hoy bastante difundida -casi diría de moda- entre los filósofos del derecho, según la cual el derecho identificado por un observador no es el mismo derecho que identifica un participante. En el presente trabajo trataré de analizar en detalle la tesis de Bayón. Lo hago por dos motivos: primero, porque considero que esta tesis es errónea y segundo, porque Bayón es uno de los filósofos del derecho más destacados de España y su presentación de la tesis es un ejemplo de claridad, lo que no siempre ocurre con los pensadores de la corriente a la que (lamentablemente) adhiere Bayón. Digo que la tesis es errónea pero no es nada fácil advertir en qué reside el error, y darse cuenta del porqué la tesis es errónea implica un importante avance en la comprensión del fenómeno jurídico. En otras palabras, no se trata de un error baladí, sino de un error fecundo e importante.

2. Bayón se propone expresamente refutar lo que él llama la tesis de la identificación objetiva del derecho que consiste en sostener que «sobre la verdad del enunciado"La norma A es derecho válido en el sistema X", entre el punto de vista de un observador mínimamente informado y el del identificado con el sistema tiene que haber coincidencia porque su posición ante ese sistema es irrelevante a efectos cognitivos». ${ }^{2}$

Esta tesis -que Bayón adjudica con toda razón al positivismo jurídico se basa, según él, en una serie de malentendidos y es en último término insostenible.

\footnotetext{
${ }^{1}$ J. C. Bayón, «Participantes, observadores e identificación del derecho», ponencia presentada al $1^{\text {er }}$ Congreso Italo-Español de Teoría Analítica del Derecho «Estructura y dinámica de los sistemas jurídicos», Imperia, abril de 1995, publicada en italiano (traducción de Riccardo Guastini) en Struttura e dinamica dei sistemai guiridici, a cura di P. Comanducci e Riccardo Guastini, G. Giappichelli Editore, Torino 1996.

${ }^{2}$ Francisco J. Laporta, «Derecho y moral: vindicación del observador crítico y aporía del iusnaturalista», Doxa 8 (1990), 131-147.
} 
Bayón comienza por presentar un modelo simplificado: una comunidad sin autoridades, en la que sólo hay reglas sociales consuetudinarias. Supongamos que un observador, tras haber estudiado durante un buen rato los comportamientos de los integrantes de esa comunidad y haber comprobado que muy pocas veces se mata a un ser humano y las pocas veces que esto ocurre se producen reacciones críticas, que no son objeto, a su vez, de reacciones críticas, llega a la conclusión de que ellos aceptan la regla «Prohibido matar seres humanos». En consecuencia, afirma «Existe la regla social "prohibido matar seres humanos "». Ahora bien, si nuestro observador preguntara a los indígenas qué regla aceptan, es posible que recibiera respuestas bien distintas. Lo que algunos de ellos aceptan es una regla más amplia («Prohibido matar cualquier ser vivo con capacidad de sufrir») y otros, una regla más restringida ( «Prohibido matar a miembros de nuestra tribu»). ¿Cuál es entonces la regla social «existente»? se pregunta Bayón. Lo único que hay es una constelación de reglas -operativas en la mente de diferentes individuos- que se solapan o convergen parcialmente, a las que llamaremos $N_{1}, N_{2} \ldots N_{n}$. En cambio, la regla social existente identificable como tal desde el punto de vista de un observador es otra regla No recortada precisamente sobre el área en que se solapan o convergen las reglas $N_{1}, N_{2} \ldots N_{n}$ y que puede no coincidir con ninguna de ellas. De allí se desprende que la regla social que «existe» para el observador es distinta de las múltiples reglas sociales que manejan los participantes.

3. Bayón señala una «dificultad adicional» que se plantea al observador que quiere identificar las reglas sociales. Esta dificultad proviene de la «intrincada relación entre normas y lenguaje»: lo que los individuos aceptan son normas y no meras formulaciones normativas. Normas son contenidos significativos que se obtienen por abstracción de las expresiones lingüísticas usadas para formularlas (formulaciones normativas). Si bien las normas sólo son expresables mediante el lenguaje, no tenemos acceso directo a las normas, es decir, a los significados de las expresiones lingüísticas; en forma directa sólo podemos conocer los enunciados mediante los cuales los participantes verbalizan sus actitudes normativas.

Ahora bien, para establecer el significado de un enunciado hay que usar reglas semánticas de designación de los términos descriptivos del lenguaje. Es claro que el observador ansioso de identificar las reglas sociales existentes debe usar las mismas reglas semánticas que los participantes. Pero no hay ninguna garantía de que todos los participantes usen las mismas reglas semánticas. (Cabe agregar que tampoco hay garantía alguna de que los mismos individuos usen las mismas reglas semánticas en momentos diferentes.) En otras palabras, no hay un conjunto perfectamente idéntico de reglas de designación que los usuarios del lenguaje comparten. Las reglas semánticas 
pueden variar y de hecho varían de un usuario a otro (y de un momento temporal a otro; este agregado le debo a Germán Sucar). Esto significa que el observador no puede aspirar más que a la formulación de una regla semántica «RS0» que recoja el núcleo central en el cual convergen las distintas reglas semánticas $\mathrm{N}_{1}, \mathrm{~N}_{2} \ldots \mathrm{N}_{\mathrm{n}}$, usadas por los participantes. Tenemos aquí la misma situación que en el caso de las reglas sociales.

4. Tengo la impresión de que calificar esta dificultad de «adicional» es un eufemismo. Me parece que se trata de un problema de capital importancia, que conviene analizar en detalle. La tesis de Bayón respecto del lenguaje admite por lo menos dos interpretaciones: una fuerte y una débil.

Trataré de mostrar que en la interpretación fuerte la tesis de Bayón lleva a consecuencias totalmente inaceptables y que en su interpretación débil esa tesis resulta casi trivial.

La interpretación fuerte consiste en tomar en serio la afirmación de Bayón de que «las reglas semánticas usadas por cada miembro de una comunidad de hablantes son inasibles o inalcanzables para un observador». Esto implica que son igualmente inasibles o inalcanzables para los demás miembros de la comunidad. De ahí se sigue que no hay un lenguaje común a los integrantes del grupo social y toda comunicación, tanto entre los miembros del grupo, como entre ellos y el observador, se toma no sólo problemática, sino imposible. En rigor, cada hablante usa un lenguaje privado, inaccesible para los demás. No puedo discutir aquí el problema de la posibilidad de un lenguaje privado, pero aún suponiendo que tal lenguaje fuese posible, la tesis de Bayón (en su interpretación fuerte) nos llevaría a un subjetivismo extremo, bastante más radical que el idealismo de Berkeley.

Dudo mucho que Bayón, a pesar de expresar cierta simpatía por lo que él llama «subjetivismo epistemológico», estaría dispuesto a aceptar todas las consecuencias de un subjetivismo tan radical. Porque en tal caso no sólo no habría reglas sociales, sino tampoco habría objetos físicos: árboles, casas, perros... Pues si no tenemos un lenguaje común, ¿cómo podemos saber si nuestros congéneres ven el mismo árbol que veo yo desde mi ventana? No cabe duda de que las sensaciones visuales que tienen varias personas que miran en esa dirección son distintas, pero a pesar de tener sensaciones distintas, decimos que vemos el mismo árbol y que las diferencias se deben a distintas posiciones de los observadores, a la incidencia de la luz, etc. Esto es posible porque podemos preguntar a los observadores qué es lo que ven y si las respuestas son coincidentes, si dicen que ven un árbol con hojas verdes, con un tronco gris, de tal forma, etc., decimos que hay allí un árbol. Si las respuestas no coinciden (por ejemplo, si yo veo que las hojas son verdes y mi amigo dice que son amarillas), esto se atribuye a algún factor de perturbación en el observador (un defecto de la visión como daltonismo 
o una enfermedad como ictericia). Pero si no tenemos un lenguaje compartido, si es imposible descubrir a qué se refiere el otro cuando usa términos como «árbol», «hoja»o «verde», porque las reglas de designación de esos términos son inaccesibles para mí, no hay tal cosa como objetos físicos que permanecen idénticos para distintos observadores, pese a que éstos últimos tienen sensaciones visuales diferentes.

La tesis fuerte de Bayón va mucho más allá del «subjetivismo epistemológico» que concibe los objetos físicos como construcciones lógicas a partir de datos sensoriales. Para hablar de construcciones lógicas es condición necesaria poder comparar los datos sensoriales de distintos sujetos: si el árbol que yo veo en el jardín no es más que una construcción conceptual de una imagen visual Io que recoge el área de convergencia de las distintas imágenes $\mathrm{I} 1, \mathrm{I} 2 \ldots \mathrm{In}$, que se forman en la retina de distintos observadores (complementada con las correspondientes sensaciones táctiles, olfativas, etc.), entonces no hay objetos físicos ni siquiera como construcciones conceptuales, si no se puede comparar los distintos datos sensoriales. Y si no hay un lenguaje común, no es posible tal comparación.

La estrategia de Bayón para demostrar que el derecho identificado por un observador es distinto del derecho que identifica cada participante, esto es, para probar la falsedad de la tesis de la identificación objetiva del derecho, consiste en mostrar que las reglas sociales existentes no son «hechos dados», sino construcciones conceptuales del observador. Ahora bien, usando el mismo argumento que emplea Bayón se podría demostrar que no hay árboles como «hecho dado», que sólo hay distintos conceptos de árbol operativos en las mentes de los individuos que convergen en parte y un observador sólo puede construir un concepto de árbol que recorte el área de coincidencia y que, por lo tanto, es distinto de los árboles de los que hablan los participantes. Sin embargo, aunque el concepto de árbol es vago y esto quiere decir que pueden producirse discrepancias respecto de casos atípicos entre los hablantes de un mismo lenguaje, esto no implica que no haya un concepto de árbol común a ellos. Si para la existencia de un significado (concepto) compartido exigiéramos coincidencia total, no habría conceptos compartidos.

Si aceptamos la tesis de Bayón en su versión fuerte, resultaría no sólo que todos los objetos que nos rodean, las casas, los árboles y los perros tampoco son «hechos dados», sino que -al igual que las reglas sociales- ni siquiera son construcciones conceptuales. En consecuencia, la tesis de la igualdad de posibilidades epistémicas que Bayón juzga correcta y que dice que «dado un hecho el conocimiento del mismo es una cosa y la actitud práctica que se adopte ante él otra distinta, y que por ello mismo constituye un serio error mezclar ambas cuestiones» pierde todo sentido, puesto que 
para la concepción de Bayón (en su interpretación fuerte) no habría nunca «hechos dados» y lo que es más grave ni siquiera habría construcciones conceptuales.

Pero hay más. Si realmente las reglas semánticas del lenguaje que usa un hablante son inaccesibles para los demás, surge la pregunta: ¿cómo puede el observador saber qué reglas aceptan los distintos participantes? ¿Cómo sabe que la regla R0 que él construye recoge el área de convergencia y unión de las reglas que operan en las mentes de los participantes? Evidentemente sin lenguaje común no hay comunicación y sin comunicación es imposible saber qué ocurre en la mente del otro. Pienso que estas consecuencias convierten en insostenible la tesis fuerte de Bayón.

5. En la interpretación débil, la tesis de Bayón consiste en afirmar que no hay coincidencia total entre las reglas semánticas del lenguaje que usan los distintos hablantes y que esas reglas no son completamente accesibles para el observador y, por ende, para los otros hablantes. ${ }^{3}$ En esta versión de la tesis habría un lenguaje compartido, pero ese lenguaje común estaría teñido por un matiz de subjetividad irremediable. Habría coincidencias, pero nunca habría coincidencias completas. Esto parece ser suficiente para sustentar la tesis de Bayón acerca de la radical diferencia entre las reglas que acepta cada uno de los participantes y la regla que construye a partir de aquéllas el observador.

Creo, sin embargo, que Bayón parte de una hipótesis equivocada. La distinción entre observadores y participantes no es tan absoluta y tajante como la presenta Bayón. Para decirlo en una forma muy comprimida: en una sociedad, si bien puede haber observadores puros, no hay tal cosa como un participante puro, porque todo participante es también un observador. Cabe recordar que estamos hablando de una comunidad, un grupo social, cuyos miembros no son ermitaños que viven en cuevas distantes entre sí, sino que están en permanente contacto unos con otros. $\mathrm{Y}$ este contacto supone algún tipo de comunicación, es decir, un lenguaje común que ellos -aunque en forma imperfecta- comparten.

No hay que olvidar que lo que los distintos aceptantes aceptan no son reglas puramente subjetivas que sólo valen para ellos, sino reglas sociales, es decir, reglas que el aceptante cree que son aceptadas por todos o por lo menos por la mayoría de los miembros del grupo social. ¿En qué se sustenta

\footnotetext{
${ }^{3}$ Bayón dice textualmente: «Y, en sentido estricto, las reglas semánticas usadas por cada miembro de una comunidad de hablantes son inasibles o inalcanzables para un observador, puesto que, por un lado, la contemplación del modo en que las usa no permite su identificación completa; y, por el otro, el intento por parte de quien las usa de expresarlas no puede realizarse más que, a través de un lenguaje que a su vez ha de ser interpretado». Esto parece sugerir la posibilidad de una identificación incompleta.
} 
esta creencia? Obviamente en su observación de lo que dicen y hacen sus congéneres. En otras palabras, todo participante observa permanentemente el comportamiento de los demás participantes y, en consecuencia, corrige su versión de las reglas aceptadas por él en función de lo que dicen y hacen los demás miembros del grupo y de las reglas que ellos aceptan o dicen aceptar. En consecuencia, no hay tal cosa como R1, una regla que el participante acepta de una vez para siempre. Lo que hay es un permanente proceso de identificación de la regla en el transcurso del cual el aceptante modifica la regla aceptada por él en consonancia con las reglas aceptadas por otros participantes, es decir, R1 tiende a converger, con el tiempo, con las reglas que aceptan otros miembros del grupo $\left(\mathrm{R}_{2} \ldots \mathrm{R}_{\mathrm{n}}\right)$, lo cual quiere decir que todas estas reglas que en un principio eran tal vez bastante diferentes se aproximan con el tiempo cada vez más para volverse prácticamente indistinguibles. Como este proceso se opera en todos los miembros de la comunidad, las reglas que cada uno de ellos acepta tienden a unificarse. Por lo tanto, la regla No del observador no difiere mayormente de las reglas de los aceptantes.

Así en el caso de la comunidad primitiva de Bayón el participante que al comienzo aceptaba la regla más amplia («Prohibido matar seres vivos con capacidad de sufrimiento»), al observar que sus congéneres matan alegremente mosquitos, cucarachas y vacas, corrige su regla, admitiendo que los seres vivos que no sean humanos no entran en el ámbito de la prohibición de la regla. También es muy probable que el otro participante que originariamente aceptaba la versión restringida de la regla («Prohibido matar a los miembros de mi tribu»), con el tiempo corrija su versión de la regla, incluyendo en su ámbito de prohibición a tribus vecinas y, más tarde, a todos los seres humanos. Para acelerar este proceso de unificación suelen introducirse dos instituciones básicas en la vida jurídica de una comunidad: una legislatura que promulga formalmente las reglas generales y los jueces que, al aplicar las reglas generales a casos concretos, deciden en cada caso cómo han de ser interpretadas esas reglas. La formulación oficial de las reglas mitiga, pero no soluciona el problema, pues sólo le da certeza a la formulación normativa, pero queda abierta la cuestión de saber qué norma es expresada en esa formulación. Para saber esto último hay que interpretar la formulación normativa, es decir, asignarle un significado definido y no queda excluida la posibilidad de que distintos intérpretes (o los mismos intérpretes en distintas ocasiones) atribuyan normas diferentes a la misma formulación normativa. Pero esto ocurre con todas las expresiones lingüísticas: siempre es posible que distintos hablantes atribuyan a un término o a una oración un significado algo diferente. Esto no impide que tengan un lenguaje compartido, siempre que las diferencias sean menores que las coincidencias. Lo 
que se requiere para la existencia de un lenguaje común es que haya un núcleo central coincidente, aún cuando este núcleo esté envuelto en un halo de indeterminación donde puede haber discrepancias.

Tiene razón Bayón en sostener que este problema se presenta por igual para las normas consuetudinarias y para las directivas promulgadas oficialmente por las autoridades (normas legisladas). Dicho sea de paso, no me es claro por qué Bayón considera que éstas últimas constituyen «el nivel más superficial del fenómeno social que representa el derecho» y que no es posible su comprensión «si no se toman en cuenta las densas y complejas prácticas sociales que subyacen a la emisión y aplicación de aquellas directivas». Ciertamente no comparto esta idea y tengo una fuerte sospecha de que es la tesis opuesta la que se acerca más a la verdad. Pues por razones metodológicas (y tal vez temperamentales) me parece que siempre conviene comenzar por lo más sencillo y claro y no por lo complejo y denso. Pero sea cual fuere la situación, lo cierto es que el problema de la identificación de las normas jurídicas vigentes en una comunidad es igual o muy parecido para las normas consuetudinarias y para las normas legisladas, precisamente por las razones dadas por Bayón: porque si por normas entendemos no meras formulaciones normativas, sino sus significados, la identificación de las normas legisladas depende de las reglas semánticas del lenguaje usado y éstas ultimas no son más que una especie de reglas sociales y, por lo tanto, comparten los mismos problemas que se suscitan respecto de la identificación de las reglas prescriptivas consuetudinarias.

En ambos casos -sea que se trate de formular normas consuetudinarias o de interpretar normas formuladas oficialmente- este proceso de unificación requiere un tiempo a veces largo y la coincidencia tal vez no llegue nunca a ser perfecta. Sin embargo, lo fundamental es esta coincidencia básica acerca de la norma, es decir acerca del significado que se atribuye a la formulación normativa (sea ésta una formulación «oficial» de la autoridad legislativa o una formulación extraoficial de una norma consuetudinaria).

6. Acabo de decir que a pesar de este proceso de aproximación progresiva pueden subsistir algunas diferencias entre la regla que acepta un participante y las que aceptan otros participantes y, por lo tanto, en tal caso habrá una diferencia entre esas reglas y la regla No del observador. Esto suena a la admisión de la tesis de Bayón, tal vez en forma algo atenuada. Para ver que esto no es así, tenemos que aclarar bien en qué consiste esa diferencia remanente entre las reglas de los distintos participantes. Esta diferencia -cuando la hay- se manifiesta únicamente en la aplicación de la regla a casos marginales o atípicos. Respecto de los casos claros no hay ninguna diferencia; todos estarán de acuerdo en la aplicación o no de la regla. En los casos marginales o casos de penumbra (para usar una expresión feliz de 
Hart) pueden surgir diferencias. Pero esto no autoriza a sostener que se trata de diferentes reglas. Dicho en otras palabras, se trata aquí del conocido fenómeno de la vaguedad o textura abierta del lenguaje: todos los términos descriptivos del lenguaje, es decir, todas las expresiones que se usan para referirse a la realidad son en mayor o menor medida (al menos potencialmente) vagas. Pero esto sólo significa que pueden presentarse (o imaginarse) casos atípicos en los que no se sabe si la norma se aplica o no. El término «matar», por ejemplo, es ciertamente vago en este sentido. Esto no quiere decir que uno no conoce el significado de esa palabra; todos coincidimos en que clavar un cuchillo en el corazón del otro o colocar una bomba en el avión que luego explota en vuelo es matar. Sin duda, pueden presentarse casos dudosos, en los que pueden surgir discrepancias. ¿Es matar dejar que un campesino indio se muera de hambre sin ayudarle? ¿Mata el que no impide que otro tome un avión del que sabe que tiene desperfectos y el otro muere a causa de un accidente? Es posible que estos casos sean resueltos de manera diferente por los distintos aceptantes de la norma «Prohibido matar seres humanos». Pero esto no autoriza a sostener que no existe un significado «objetivo» de la palabra «matar», compartido por los hablantes de un lenguaje, ni se puede concluir que los diferentes hablantes tienen distintos conceptos de matar.

Para la existencia de reglas sociales, sean éstas consuetudinarias o legisladas, es esencial la existencia de un acuerdo sobre los casos claros que caen dentro del núcleo central de la norma. Esto ocurre no sólo con todas las reglas sociales, tanto prescriptivas, como conceptuales, sino con todos los conceptos (descriptivos) de nuestro lenguaje. Así como la vaguedad del concepto de mesa no impide decir que existen mesas, como la que tengo enfrente en estos momentos (que claramente es un «hecho dado»), la vaguedad del concepto de norma no impide hablar de normas existentes. Y las posibles discrepancias respecto de situaciones atípicas no prueban más que eso: que el concepto de norma es vago. Pero no prueba en absoluto que el observador tenga un concepto de norma (o de mesa) distinto del que manejan los participantes.

Por consiguiente, la tesis de Bayón (en su variante débil) se reduce en última instancia a la comprobación de que el concepto de norma adolece de vaguedad. Esto no parece ser una novedad muy excitante. 